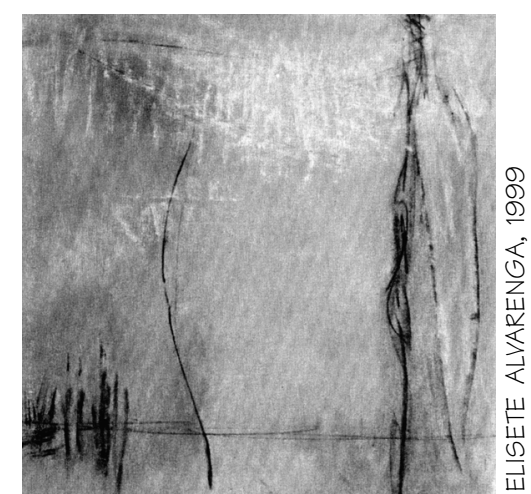

\title{
Saúde e produção de sentidos no cotidiano: práticas de mediação e translingüística bakhtiniana
}

Luiz Augusto Vasconcelos da Silva ${ }^{1}$

SILVA, L. A. V. Health and the creation of meaning in daily life: mediation practices and bakhtinian translinguistics, Interface - Comunic, Saúde, Educ, v.7, n.13, p.135-48, 2003.

This article discusses some concepts and uses of semiotics in the field of Public Health focusing mainly on texts by the Russian writer Mikhail Bakhtin. These reflections encompass specific topics prepared after I had taken part in an ethnographic research project about the practice of epidemiological investigation. This study emphasizes the contribution of semiotics to the analytical construction of the different meanings of health. It presents a synthesis of narrative fragments as examples of the shift in health texts. It highlights Bakhtin's current influence allowing us to think about how different agents participate as mediators in the construction of meanings of health. Thus, human agents - social subjects - with their different cultural backgrounds are engaged in the production of health-disease-care models, because they share, dispute and negotiate points of view in a continual process of creating meaning in daily life.

KEY WORDS: Communication; Semiotics; Public Health; meanings of health; concept formation.

A partir da participação em um projeto de pesquisa etnográfica sobre a prática de produção epidemiológica, busca-se discutir alguns conceitos e usos da Semiótica no campo da Saúde Coletiva, focalizando principalmente os textos do escritor russo Mikhail Bakhtin. Destaca-se a contribuição da Semiótica para a análise de sentidos de saúde e apresenta-se uma síntese de fragmentos de narrativa como exemplos de deslocamento de textos de saúde. Ressalta-se a atualidade de Bakhtin ao nos fazer pensar sobre a participação dos diferentes agentes como mediadores na construção de sentido. Dessa forma, os agentes humanos - sujeitos sociais - em suas diversas trajetórias culturais, encontram-se engajados na produção de sentidos de saúde-enfermidade-cuidado, pois compartilham/disputam/negociam pontos de vista ou tendências, num processo contínuo de produção de sentidos.

PALAVRAS-CHAVE: Comunicação; Semiótica; Saúde Coletiva; sentidos de saúde; formação de conceitos.

${ }^{1}$ Professor, Departamento de Psicologia, Universidade Federal da Bahia (UFBA); Pesquisador Associado, Instituto de Saúde Coletiva/UFBA. <luisvascon@uol.com.br> 


\section{Introdução}

Este artigo encontra-se vinculado a estudo etnográfico sobre a prática cotidiana de produção de dados e textos epidemiológicos, realizado em 1998, tendo como ponto de partida dois projetos de investigação epidemiológica do Instituto de Saúde Coletiva, da Universidade Federal da Bahia ${ }^{2}$. Essa experiência etnográfica resultou na minha dissertação de mestrado, intitulada produção e comunicação de sentidos-de-saúde em práticas concretas de investigação epidemiológica'. Longe de 'fixar' significados ou buscar esta ou aquela representação do conceito de saúde entre epidemiólogos e seus pares, busquei destacar as 'ações conectadas' entre os agentes cotidianos de pesquisa $e$ as 'práticas discursivas' na mobilização de sentidos de saúde.

Foi possível, assim, desenvolver uma discussão sobre a produção de sentidos no cotidiano, com toda sua diversidade e permanência. Em contrapartida, acredito que as práticas de mobilização científica delimitam uma área específica de produção de signos e significados, uma rede mais ou menos extensa de comunicação na qual os sentidos de saúde adquirem, em etapas posteriores, uma forma peculiar de uso científico. Dessa maneira, produz-se um 'repertório empírico' - sob a forma de doença - deixando para trás uma possível 'experiência' sobre outros sentidos de saúde.

Certamente, as considerações que proponho desenvolver limitam-se a alguns aspectos que compuseram minha dissertação. Preferi, assim, abordar separadamente os textos bakhtinianos, com o objetivo de torná-los menos estranhos ao campo da Saúde Coletiva, viabilizando também outras possibilidades de 'tradução' de signos de saúde.

No que concerne à produção e comunicação de sentidos de saúde, pretendo salientar uma atividade contínua que inclui o próprio 'agenciamento humano' sobre o mundo e a natureza, delimitando e/ou modificando práticas cotidianas de saúde ou modos de vida. Na confusão cotidiana de produção científica - vozes/atividades/textos/ruídos - são incorporados (e gerados) novos modelos e estratégias de produção de conhecimento. De forma similar, as 'atividades de promoção de saúde' significam, potencialmente, processos de mediação em que os agentes humanos (na diversidade de mediadores) compartilham/disputam/negociam pontos de vista ou tendências, podendo-se alcançar - mesmo provisoriamente - alguns propósitos 'comuns' de ação ou efeitos de sentido.

\section{O dialogismo bakhtiniano}

É difícil definir ou enquadrar os textos do semioticista russo Mikhail Bakhtin (1895-1975), em uma linha precisa de pesquisa, como bem atestam Clark \& Holquist (1998) em sua biografia de referência no Ocidente. Teórico do romance, da literatura, lingüista, filósofo da linguagem, foram muitas as tentativas de cooptá-lo no meio de uma obra tão difusa. Talvez sua melhor definição tenha sido indicada por eles mesmos: "Bakhtin não se via a si mesmo como um teórico da literatura, em primeiro lugar. O termo que julgava mais próximo daquilo que estava tentando fazer era o de antropologia filosófica" (Clark \& Holquist, 1998, p.37). Conforme enfatizada em sua biografia, os autores denominam sua filosofia da linguagem de translingüística, na medida em que estava mais preocupado

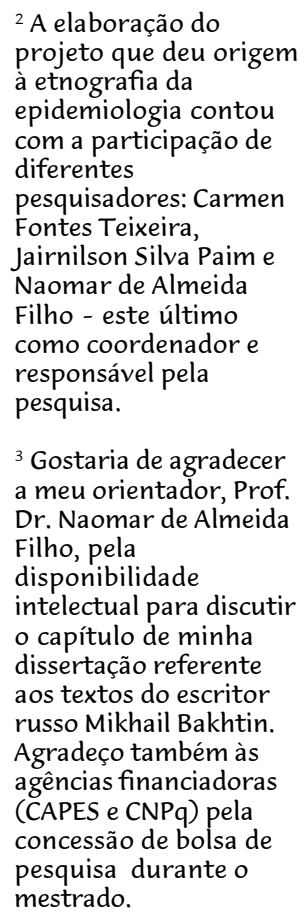

${ }^{3}$ Gostaria de agradecer a meu orientador, Prof. Dr. Naomar de Almeida Filho, pela disponibilidade intelectual para discutir o capítulo de minha dissertação referente aos textos do escritor russo Mikhail Bakhtin. Agradeço também às agências financiadoras (CAPES e CNPq) pela concessão de bolsa de pesquisa durante o mestrado. 
${ }^{4}$ A partir desse ponto de vista, similarmente à linguagem, também nos constituímos responsivamente: "o nosso si mesmo é um fenômeno de fronteira. Na prática, é menos uma entidade e mais uma estratégia ou conjunto de estratégias, um modo ou um conjunto característico de modos de responder aos outros ao nosso redor. Algo que só aparece nesse ponto de contato com aqueles outros. Ou se é uma entidade, é uma com fronteiras constantemente disputadas e mutáveis" (Shotter, 1996, p.223). com a comunicação, com as conexões e articulações entre as variedades $e$ outridades, enfim, com os processos de mediação.

Respaldados nos escritos de Bakhtin e nas críticas contundentes a uma tradição lingüística quer seja formalista ou subjetivista, diferentes autores passam a enfatizar o caráter comunicativo da linguagem, como um processo relacional, concreto e ativo (Burkitt, 1998; Gergen, 1996, 1997; Shotter \& Billig, 1998) ou mesmo retórico-responsivo (Shotter, 1993, 1996) 4 . Para compreender a produção de textos e argumentos científicos, ou ainda a construção de sentidos no cotidiano, enfatiza-se uma dimensão pragmática da linguagem, situada histórica e culturalmente: "as palavras começam a ter seus significados apenas dentro de contextos de relações contínuas" (Gergen, 1997, p.49).

Entre os fragmentos difusos de Bakhtin, que se misturam às vozes de seus interlocutores, por exemplo, com a publicação do livro Marxismo e Filosofia da Linguagem, na década de 1920, sob a autoria de Volochínov, aparece de forma contundente esta preocupação com a dinâmica viva do signo, com as suas 'formas de vida' - situação social e contextos possíveis de uso (Bakhtin, 1999a) - extrapolando as formas fechadas, isoladas e monológicas das estruturas de análise lingüísticas. É o que sintetiza Bakhtin (1997, p.350) quando afirma:

A palavra (e em geral, o signo) é interindividual. Tudo o que é dito, expresso, situa-se fora da "alma", fora do locutor, não lhe pertence com exclusividade. Não se pode deixar a palavra para o locutor apenas. $\mathrm{O}$ autor (o locutor) tem seus direitos imprescritíveis sobre a palavra, mas também o ouvinte tem seus direitos, e todos aqueles cujas vozes soam na palavra têm seus direitos (não existe palavra que não seja de alguém). A palavra é um drama com três personagens (não é um dueto, mas um trio).

A constituição social do signo fundamenta, pois, a relação dialógica no processo contínuo de produção de sentido. Essa dialogia implica a compreensão do próprio enunciado, visto que

\footnotetext{
a palavra quer ser ouvida, compreendida, respondida e quer, por sua vez, responder à resposta, e assim ad infinitum. Ela entra num diálogo em que o sentido não tem fim (entretanto ele pode ser fisicamente interrompido por qualquer um dos participantes). (Bakhtin, 1997, p.357)
}

Ao considerar o enunciado como um elo na cadeia de comunicação - como unidade da comunicação discursiva - Bakhtin posiciona a palavra no fluxo da 'conversação cotidiana', sendo orientada/antecipada para e por uma (futura) palavra resposta. Dessa maneira, ainda que formada em uma atmosfera já falada, da língua, ao mesmo tempo é determinada pelo que ainda não foi dito (Bakhtin, 1998, p.280). Assim, como atividade viva, o enunciado dirige-se a alguém, está voltado para o destinatário, não podendo ser considerado como puramente individual:

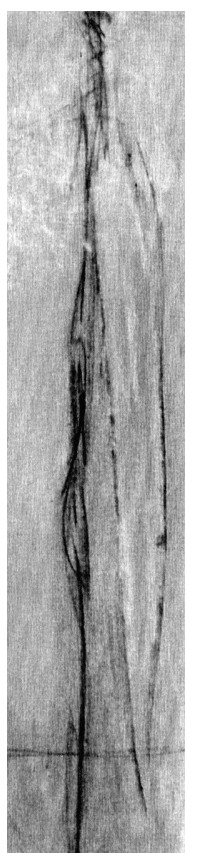




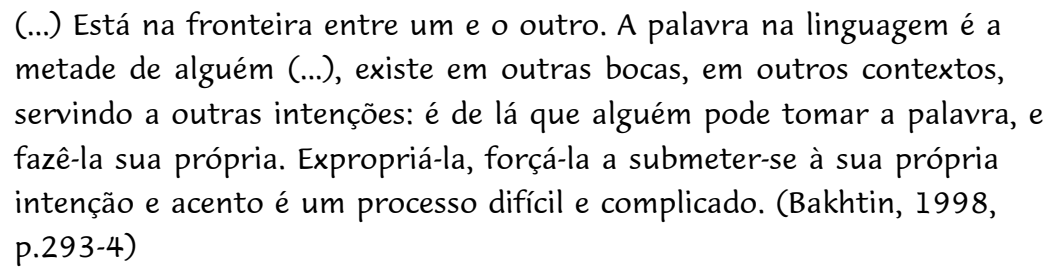

O conceito de heteroglossia de Bakhtin (1998) busca cobrir esta multiplicidade de vozes sociais $e$ a extensa variedade de relações $e$ interrelações, orquestrada dialogicamente, onde forças centrípetas (que unificam e centralizam o mundo verbal-ideológico) e as forças centrífugas (processos ininterruptos de descentralização e diferença, 'desunião'), em todo enunciado concreto, se (des)encontram. Assim, a 'heteroglossia' possibilita perceber o que está na margem, incorporando as formas vivas da linguagem, como processo formativo, flexível, cambiante.

Dessa forma, o processo da fala deve ser compreendido em uma perspectiva mais ampla (como processo da comunicação cultural). Diferentemente do sistema da língua, as práticas discursivas são formas então de comunicação, num processo ininterrupto de interação verbal (nas situações concretas, que inclui o não-verbal). É nesse sentido que "a língua como sistema estável de formas normativamente idênticas é apenas uma abstração científica que só pode servir a certos fins teóricos e práticos particulares. Essa abstração não dá conta de maneira adequada da realidade concreta da língua" (Bakhtin, 1999a, p.127). Essa perspectiva de análise estende-se para a compreensão dos 'enunciados' como processo dialógico de produção de sentidos, para as práticas concretas de vida das palavras e atos (signos).

Entretanto, alguns aspectos devem ser mais bem desenvolvidos em se tratando da atividade de mediação sígnica. Nessa perspectiva, a dialogia bakhtiniana apresenta-se de forma inconclusa quando buscamos conectar natureza e cultura, ainda que seus escritos tenham se mostrado de muita relevância nos estudos sobre a 'comunicação humana', pontuando a abertura da língua à vida:

\footnotetext{
apenas o contato entre a significação lingüística e a realidade concreta, apenas o contato entre a língua e a realidade - que se dá no enunciado provoca o lampejo da expressividade. Esta não está no sistema da língua e tampouco na realidade objetiva que existiria fora de nós. (Bakhtin, 1997, p.311)
}

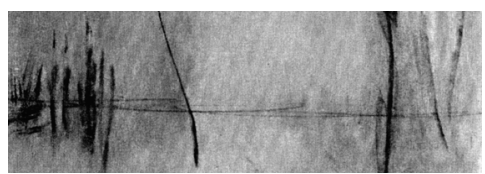

\section{Para além do limite bakhtiniano}

Em notas originárias da década de setenta do século XX, talvez buscando ampliar/ esclarecer uma perspectiva de dialogismo para além da comunicação verbal, Bakhtin (1999b, p.138) especifica três tipos de relações: relações entre objetos (fenômenos e coisas, relações causais, lógicas e lingüísticas etc.), relações entre sujeito e objeto e relações entre sujeitos (relações dialógicas entre enunciados, relações éticas, relações entre consciências, verdades etc.). Entretanto, uma relação pode se transformar em outra, sendo possível 'personalizar' muitas relações objetais e transformá-las no terceiro tipo.

De fato, a perspectiva bakhtiniana preocupa-se mais com os contextos concretos de produção de sentido e de mediação sígnica tendo como ponto de partida o 
aspecto pragmático da linguagem. Bakhtin busca enfatizar o terreno interindividual ou social do signo, principalmente quando diz que "todas as manifestações da criação ideológica - todos os signos não-verbais - banhamse no discurso e não podem ser nem totalmente isoladas nem totalmente separadas dele" (Bakhtin, 1999a, p.38).

Se o dialogismo bakhtiniano não pode ser confundido com dialética, uma vez que o mesmo enfatiza o "caráter polifônico dessa relação exibida pela linguagem" (Brait, 1997), não podemos também resumi-lo puramente/ simplesmente a uma relação diádica, a um duelo de forças, como alguns leitores parecem enfatizar; por exemplo, a semioticista Santaella (1985). Podemos, assim, enriquecer e atualizar o dialogismo bakhtiniano considerando a atividade de mediação e tradução sígnica, que envolve a própria interatividade dos signos culturais, como processo contínuo de "migração de formas" (Machado, 1995, p.22). Conforme sugerem Clark \& Holquist (1998, p.36-7), ao distinguirem Bakhtin de uma tradição filosófica sobre a diferença, podemos compreender a atividade de mediação a partir de "diferenças na simultaneidade"; e assim, como concebeu Bakhtin, destacar a interação de forças, ao invés de pensá-las como mutuamente exclusivas.

Diferentemente de Bakhtin, o semioticista americano Charles Peirce desenvolve uma definição lógico-abstrata do signo ao explicitar a relação triádica entre signo-objeto-interpretante. Todavia, podemos assinalar alguns possíveis equívocos quando relacionamos atividade ou ação de signos (semiose) à relação com o intérprete/interpretante. Se o interpretante não se confunde com um intérprete, já que "o interpretante é uma propriedade objetiva que o signo possui em si mesmo, haja um ato interpretativo particular que a atualize ou não" (Santaella, 2000, p.63), deve-se destacar que no processo de produção dos 'saberes cotidianos', que inclui a própria produção de informação científica, os agentes humanos participam 'ativamente' na tradução de signos. Dessa forma, como chamou a atenção Merrel (1998), os interpretantes que não gozam de alguma interação com agentes semióticos (humanos e outras classes de organismos) não são genuínos - "o agente semiótico, como vaso comunicante, tem a função de um intermediário para que haja mediação entre as três entidades que compõem um signo em seu sentido cabal' (p.48-9). O aspecto comunicativo dos signos não se confunde, portanto, com uma relação de significação pré estabelecida (Deely, 1990).

Vale destacar, então, a seguinte definição de signo em Peirce (1999, p.74):

qualquer coisa que conduz alguma outra coisa (seu interpretante) a referir-se a um objeto ao qual ela mesma se refere (seu objeto), de modo idêntico, transformando o interpretante, por sua vez, em signo, e assim sucessivamente ad infinitum.

Na perspectiva então do próprio agente semiótico/intérprete/interpretante, deve-se compreendê-lo também como signo, gerando outros signosinterpretantes. Sobre a relação intérprete/interpretante em Peirce, assinala Merrel (1998, p.49):

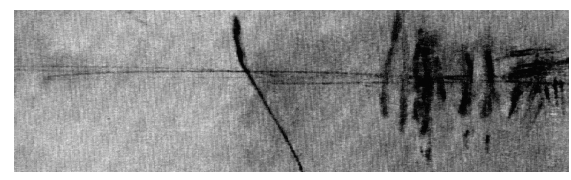

Um signo tem que ser algo que se refere a algo para alguém em algum respeito ou capacidade. Se esse alguém não está presente, então o 
signo goza de um interpretante só em potência. Porém, cabe dizer, a fim de contas, este alguém é, por si, nada mais nem nada menos que outro signo, outro interpretante, para algum outro signo, e, por onde, para outro intérprete.

Nesse aspecto, há uma convergência entre Bakhtin e Peirce, no sentido de que o próprio pensamento está conectado a outros pensamentos. Para ambos autores, todo pensamento é dialógico, de modo mais geral, social. Santaella (1985, p.10), em relação a Peirce, diz que

\author{
a semiose ou ação sígnica é eminentemente social. Um ato \\ interpretativo, uma interpretação aqui-agora de um signo não é \\ senão um caso especial do interpretante, visto que este é, por \\ natureza, mais geral, social e objetivo do que um ato particular e \\ exclusivo de um só intérprete.
}

Por sua vez, na perspectiva bakhtiniana, "não há atos isolados na consciência. Cada pensamento está ligado a outros pensamentos e, o que é mais importante, aos pensamentos de outrem" (Clark \& Holquist, 1998, p.101).

Na mobilização de sentidos e práticas cotidianas, podemos reconhecer a ação sígnica como "crescimento contínuo e tendencialidade" (Santaella, 2000, p.74), ao mesmo tempo em que outros repertórios e estratégias interpretativas surgem em contextos de comunicação diversos. Estabelece-se aqui o desafio de não perder a perspectiva de que os agentes humanos, cotidianamente, "não emitem signos no vazio, eles falam em meio a e para outros sujeitos que, por sua vez, também falam. (...) Um bom sistema de signos é aquele que também abrange seleções contextuais" (Eco, 1999, p.188).

Nessa direção, tanto em Bakhtin quanto em Peirce o sentido surge como 'potencialmente' infinito; e nessa direção, um pode complementar o outro em se tratando de uma análise mais 'extensiva' da noção de signo, para além de uma compreensão lingüística. Na perspectiva de Peirce (1999), o 'potencialmente' deve ser compreendido a partir de um terceiro, já que no processo de tradução ou mediação, ocorre uma certa tendência/determinação do sentido em relação às 'convenções e aos hábitos'. Para Merrel (1998, p.57), por exemplo, "a terceiridade marca o desenvolvimento vital dos signos, um processo criador por meio do qual o caos se faz ordem", e assim continuamente.

A produção de sentidos, segundo o próprio Bakhtin (1997, p.413), é potencialmente infinita na medida em que "não há uma palavra que seja a primeira ou a última, e não há limites para o contexto dialógico (este se perde num passado ilimitado e num futuro ilimitado)". Para um entendimento recíproco entre locutores, entretanto, deve-se levar em consideração os gêneros do discurso, já que "todos os nossos enunciados têm formas relativamente estáveis e definitivas de construção do todo" (Bakhtin, 1999b, p.78).

O 'processo de mediação' e relacional dos signos permite, portanto, uma mobilização de novos sentidos na cadeia de comunicação cultural, isto é, pela compreensão responsiva ativa do outro (Bakhtin, 1997) ou engajamento

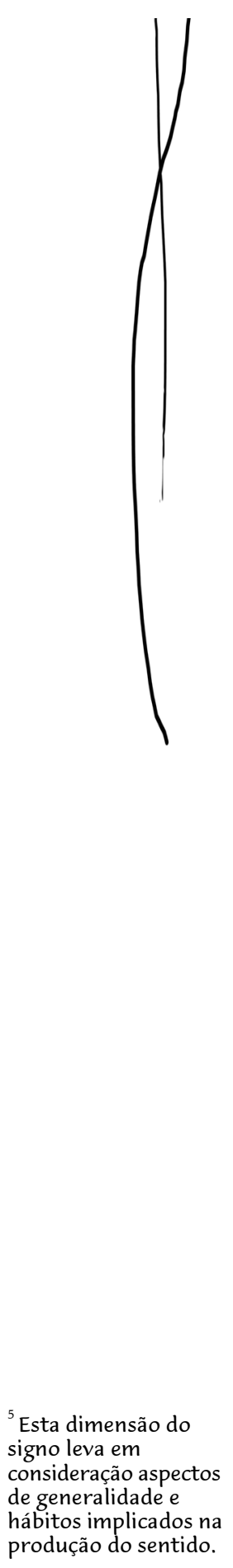


${ }^{6}$ Expressão retirada do livro Speech Genres \& Other Late Essays (Bakhtin, 1999, p.7). contínuo dos intérpretes e interpretantes (signos) na interação dialógica (Merrel, 1997, p.30). Vale ressaltar, em relação à dialogia Bakhtin-Peirce (Merrel, 1997), que os respectivos outros não são mudos, eles são atualmente ou potencialmente outros intérpretes/interpretantes engajados em um processo contínuo de tradução em contextos de cultura.

A expressão 'compreensão ativa' utilizada por Bakhtin pode ser traduzida em inglês por creative understanding ${ }^{6}$. A tradução 'entendimento criativo' sugere abertura, movimento, no 'ato compreensivo', na medida em que tende para o futuro, 'incorporando' uma potencialidade de produção do novo (novas possibilidades). Entretanto, estas expressões/traduções encontram-se interrelacionadas, sendo importante compreendê-las de forma articulada, isto é, o 'entendimento criativo' implicando uma 'atitude responsiva ativa'. Cabe lembrar, então, que

Sobre a condição/compreensão responsiva de todo enunciado, ainda que não tenha como efeito uma ação/realização imediata, Bakhtin (1999b, p. 69) esclarece: "todo entendimento real e integral é ativamente responsivo $e$ constitui nada mais do que o estágio preparatório inicial para uma resposta (ela pode ser atualizada em qualquer forma)" (grifos nossos).

Por outro lado, se o signo está vinculado ao objeto sob algum aspecto ou modo/qualidade (Peirce, 1999) e sempre 'tende' para o futuro (seu interpretante - mediatamente relacionado ao mesmo objeto), ao que ainda não é, 'apresenta-se', por conseguinte, de forma incompleta. Segundo Deely (1990, p.46), "nunca confinada àquilo que foi ou é, a semiose emerge na fronteira entre o que é e o que pode ser, ou o que poderia ter sido".

É possível, assim, ampliar a análise das práticas discursivas incluindo, de uma forma mais ampla, a linguagem (signo) não-verbal e toda uma prática constitutiva de ações entre os agentes cotidianos, nos diferentes contextos performativos. Isso implica reconhecer também os 'interlocutores' constituindo-se em diversas atividades sociais, ou em 'pautas de interação social semelhantes a jogos', conforme enfatiza Barnett Pearce (1994, p.274):

Nascemos e nos incluímos em pautas de interação social semelhantes a jogos que nós mesmos não iniciamos. Escutamo-los, começamos a sentirnos poderosamente envolvidos, aproveitamos a oportunidade de participar, e ao fim partimos, porém as conversações seguem. Creio que essa é a substância do mundo social.

Vale enfatizar que os agentes de discurso, científicos e não científicos, encontram-se engajados circunstancialmente, delineando contextos relacionais de cooperação e/ou resistência. Estes contextos constituem o que 
chamamos de momentos dialógicos implicados/constrangidos por um terceiro - pelo reconhecimento de hábitos (sociais/científicos/naturais) ou regras (metodo) lógicas. O termo 'constrangimento' é aqui utilizado como um apoio lingüístico, não podendo ser compreendido em um sentido estático, permanente, sincrônico - refiro-me à crítica feita por Pickering (1995) ao enfatizar a co-produção dos agentes (materiais e humanos) temporalmente emergentes, no contexto de produção científica. Entretanto, como 'efeitos de discurso', em diferentes situações vividas cotidianamente, há um deslocamento de termos, sugerindo limites, restrições e controle. $\mathrm{O}$ mais importante a considerar é que os agentes encontram-se engajados/situados temporalmente em atividades mutáveis e dinâmicas.

\section{Considerações sobre as teias narrativas}

Mesmo com o risco de incorrer em uma tradução/redução simplificada, gostaria de tecer breves comentários em torno de três fragmentos de narrativa retirados da etnografia sobre a produção de dados epidemiológicos. As narrativas descritas a seguir referem-se a um dos projetos de investigação epidemiológica do Instituto de Saúde Coletiva, denominado Projeto Bahia Azul, durante uma trajetória etnográfica, no ano de 1998, em que vários agentes (técnicos, coordenadores de campo, epidemiologistas e outros profissionais da Saúde Coletiva) foram acompanhados nos diferentes contextos de investigação. Cada narrativa apresenta uma perspectiva possível de análise no desdobramento de sentidos de saúde. Parto, então, da premissa de que diferentes níveis de atividade (e de linguagem) encontram-se conectados na produção 'crescente' de sentido, irredutivel às suas dimensões originárias $e$ particulares. A figura 1 apresenta este esforço de 'síntese narrativa' sobre a mobilização de textos de saúde, a partir de um engajamento coletivo ou trabalho contínuo de mediação. Essa teia de sentidos 'extravasa' o campo de discurso epidemiológico, acolhendo (e gerando) outras atividades 'difusas' no cotidiano; uma (trans)formação que indica pluralidade (e abertura) de textos de saúde.

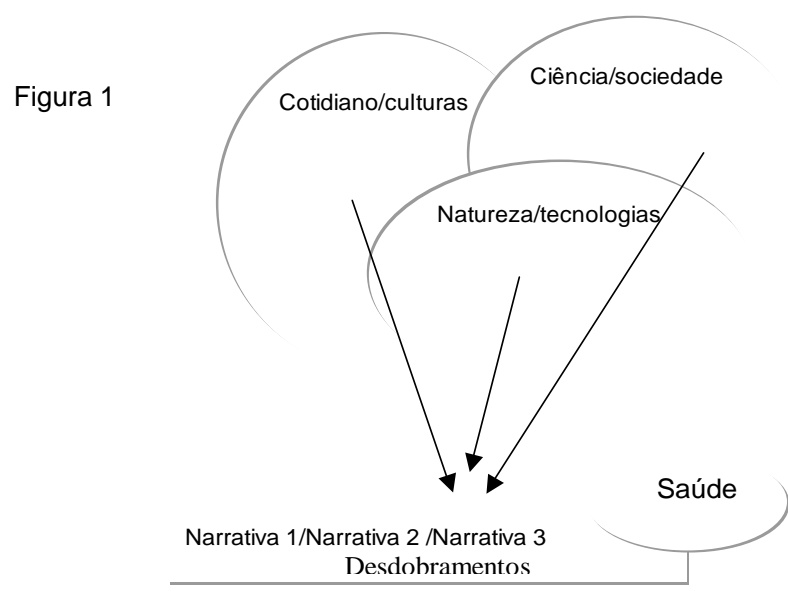

Compartilho aqui uma concepção de texto para além de seu sentido literárioverbal. Danesi \& Perron (1999, p.92), por exemplo, definem o texto como uma "colagem de signos tomados de um ou mais códigos em ordem para construir e comunicar uma mensagem". No processo de circulação $e$ compreensão de textos, são necessárias, portanto, convenções semióticas que 
estabeleçam uma ordem significante. Para os autores (Danesi \& Perron, 1999), há uma interrelação entre semiose, representação e ordem significante, isto é, uma interrelação entre a capacidade inata para produzir e compreender signos (semiose), a atividade de usar signos para referir-se a um objeto, ser etc. (representação) e o sistema comum 'providenciando' signos que influenciam e guiam representações dentro de uma cultura específica (ordem significante).

Conforme a síntese esboçada na figura 1 , vale ressaltar que as narrativas foram produzidas a partir de 'níveis de mediação' - que incluem as atividades de campo, produção de dados e informação científica. Assim, quando 'localizamos' uma rede de comunicação cultural, tendo como ponto de partida os objetos e agentes (circulantes) no cotidiano de investigação científica/ epidemiológica, de certa forma buscamos acompanhar o desdobramento dos níveis de mediação. Este foco de análise trabalha com a perspectiva de que os diversos agentes (científicos e não científicos; humanos e não-humanos) se movimentam como mediadores e se apresentam como mediados na produção de textos de saúde. Os momentos dialógicos implicados nesta produção significam, portanto, atividades de mediação ou atualização possível de sentidos de saúde. Acompanhando as ações conectadas entre os agentes humanos (por sua vez, incluindo a participação/mediação dos agentes materiais), é possível estabelecer uma 'dialogia' entre natureza e cultura/sociedade.

Nas atividades de campo, por exemplo, em que as entrevistadoras processavam os números $e$ anotações nas fichas de seguimento de crianças de 0-3 anos, chamei a atenção para uma rede de ação onde se interconectavam

${ }^{7}$ Como destacam Bruno Latour \& Woolgar (1997), o termo inscrição remete a uma operação anterior à escrita, que serve para resumir traços, números de registros, pontos, gráficos etc. textos biológicos/naturais e culturais. Dessa forma, localizei a própria entrevista como 'ato conversacional' ou espaço de negociação e de posicionamentos, buscando-se produzir inscrições ${ }^{7}$ e signos interpretativos. A 'objetivação do dado', mediante a produção de inscrições sígnicas, ocorria mediante o 'reconhecimento' de uma narrativa familiar e de hábitos sociais e científicos.

Em cotidianos de práticas científicas/epidemiológicas, localizadas histórica e culturalmente, as narrativas transitam entre a confusão, o movimento incessante de textos/dados/atividades, e o 'esforço conjunto' de agentes no processo de produção, organização e circulação (inteligibilidade) de dados $e$ informação científica. As muitas vozes que constituem e se deslocam nas narrativas expressam uma variedade de formas, 'visões' e tendências/ modelos de assimilação (potencial) do objeto saúde. As narrativas descritas a seguir referem-se a um dos projetos de investigação epidemiológica do Instituto de Saúde Coletiva, denominado Projeto Bahia Azul, durante uma trajetória etnográfica, no ano de 1998, em que vários agentes (técnicos, coordenadores de campo, epidemiologitas e outros profissionais da Saúde Coletiva) foram acompanhados nos diferentes contextos de investigação.

\footnotetext{
Narrativa 1

E aí... nós fomos lá no campo, elas ficam doidas pra... porque eu paro, eu converso, aí o morador... sempre tem aquelas figuras que são tipos os minis prefeitos, né, ou de esquerda ou de direita. Mas aí eu enveredo com eles e eles sempre "venha cá", já me mostrando tudo e eu já vou olhando tudo, analisando, tirando foto. Então eu trabalho muito assim, sempre trabalhei muito assim, e tenho uma crença de que isso daí funciona muito, entendeu? funciona muito! Eu acho que eles é que vivenciam isso que
} 
na minha dissertação de mestrado eu coloco: quem é que vivencia a realidade? Eles é que tão ali, vivenciando. Então quando enche, são eles que tão ali, vivenciando a enchente, entendeu? Quando o esgoto entope, são eles que tão lá, entrando. A comunidade (...) trabalhando na baixa do Camarugipe e enche, é um problema sério. Fizeram uma intervenção muito grande, e tal e tal, e não resolveram o problema maior da comunidade, que é o bueiro, bueiro que atravessa a BR, então quando chove, alaga tudo. Eles... a gente já registrou e já filmou, eles entraram, eles mergulharam no bueiro, retiraram aquele material todo e é aquela festa, e tome-lhe cachaça e tome-lhe feijoada pra todo mundo, porque o pessoal tem que entrar ali pra retirar todo aquele material, todo mundo vem segurar a corda (pesquisadora responsável pela avaliação ambiental do projeto Bahia Azul).

Na narrativa 1, encontramos um agente científico viabilizando uma produção de informação para o grupo de pesquisa. A partir de uma interseção de trajetórias culturais, a pesquisadora 'reconhece' o cotidiano de uma comunidade e as estratégias de ação frente às diversidades do ambiente e políticas governamentais. Não restrita a uma metalinguagem científica, uma 'experiência espontânea' é traduzida ${ }^{8}$ por meio de signos de solidariedade/cuidado e mobilização social - "festa, cachaça, feijoada todo mundo vem segurar a corda".

Quando enfatizamos as ações conectadas entre os vários agentes de pesquisa que se deslocam nesta rede de comunicação cultural, encontramos também diferentes trajetórias de usos e hábitos. Dessa maneira, ainda que haja uma tendencialidade interpretativa no contexto de investigação científica (repertórios argumentativos mais gerais), cada nova atualização pode significar uma possível abertura para outros sentidos a partir da 'perspectiva de observação' em foco. Este 'jogo conversacional', que inclui diferentes trajetórias de usos, hábitos e linguagens, desafia a própria efetividade de entendimento mútuo.

\section{Narrativa 2}

De repente uma funcionária do laboratório entrou na sala alardeando que havia encontrado uma amostra de fezes vinda da ilha que continha 2000 ovos de Ascaris por grama. Foi o suficiente para Hesse iniciar um discurso político sobre o descaso das autoridades em relação à saúde da população: "Essas crianças foram examinadas e tratadas há oito meses e hoje se encontram num estado de saúde pior que o anterior. Isto é típico de um Governo que não faz uma política básica. Vocês pensam que é por falta de dinheiro, mas não é não, é falta de vontade (Diário de campo de um bolsista de iniciação científica).

Na narrativa 2, encontramos uma trajetória de significação do dado que tende para uma dimensão macropolítica. Aqui, em se tratando de uma trajetória de linguagem e posição do agente - coordenador técnico originário do campo da sociologia - destaca-se uma 'potencialidade de discurso' sobre 'indicadores de doença' que se traduzem por uma 'qualidade social'. Quando assinalo que uma 'diversidade' de agentes está situada/ conectada no processo de produção de dados e informação científica, significa enfatizar, também, diferentes posições de interlocução. Dessa

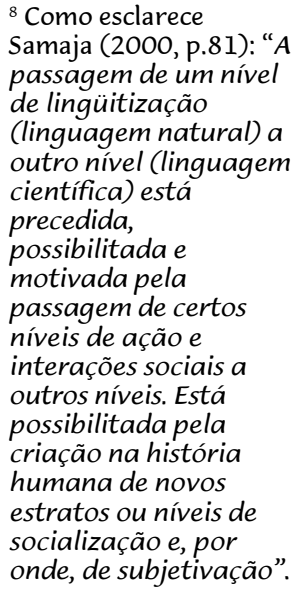

${ }^{9}$ Todos os nomes dos informantes são fictícios. 
maneira, em uma trajetória de mobilização de sentidos, os agentes humanos produzem 'signos' interpretativos de posicionamento diante do mundo, ao mesmo tempo em que estão mediados/constrangidos por 'normas' de usos científicos.

Levando-se em consideração diversas atividades e agentes que circulavam no projeto Bahia Azul, deve-se pontuar uma prática cotidiana em que pesquisador e 'sujeitos de pesquisa' encontravam-se engajados/situados na produção de textos e narrativas. Dessa maneira, delineia-se um 'campo' de posicionamentos mediante as ações conectadas entre os diferentes agentes $e$ interlocutores. Ratifico, assim, mediante os vários encontros dialógicos, um 'deslocamento possível' de posições, sentidos e demandas na produção de números/signos.

\begin{abstract}
Narrativa 3
(...) Olha, Natal do ano passado, eu tô pensando, este ano Natal a gente não vai poder estar junto, tem um menino que me pede uma árvore de Natal desde o ano passado, porque eu dei pra um outro, porque eu fiquei com tanta dó daquele menino, que ele me mostrou um folheto, um encarte do Bompreço, não era nem Bompreço na época, era...aí perguntou pra mim 'oh, que bonito, na sua casa tem árvore de Natal? árvere' (Ailícia repete pontuando o erro). Eu disse 'ah, tem árvore sim'; aí ele disse assim, 'pôxa, não tenho, você me dá uma árvore?' Aí eu tinha uma árvore lá em casa, não, era da minha (...), ela me deu, eu arranquei umas bolas, levei pra ele, ele ficou tão feliz com a árvore, virou e disse 'não tem caixa? por que como é que eu vou guardar pro ano que vem?' cinco anos o menino. Fiquei com tanta pena dele, aí o outro (...) perguntou 'você me dá uma?' 'Agora só no ano que vem, porque já acabou o Natal'... ele ficava...porque ele ia pra casa da vizinha, ficava parado, olhando as luzinhas (...) como é aquelas luzinhas, como é o nome, luminária, eu pedi pra meu marido pra dá um jeitinho e tudo, aí ficou bastante, levei, e conseguiu colocar tudo na árvore, aí ele ficou encantado, feliz da vida, por uma árvore de Natal (...) (Entrevistadora de campo).
\end{abstract}

Na narrativa 3, encontramos uma entrevistadora de campo interagindo com duas crianças no cotidiano de investigação epidemiológica. Para além de um contexto de produção de dados e inscrições, ocorre um posicionamento diante do outro, pelo qual é possível produzir signos/sentidos de 'felicidade', 'encantamento', mediados culturalmente. Ocorre aqui uma 'trilogia' entre criança, natal e árvore em um deslocamento possível de signos-interpretantes para além do objeto doença.

Responsáveis, de certa forma, pela manutenção e circulação dos dados referentes à incidência de diarréia em crianças de 0-3 anos, pelas visitas contínuas para o preenchimento de fichas do seguimento, as entrevistadoras colaboravam para a manutenção da própria coorte ao estabelecerem um diálogo de confiança com as informantes ou 'abertura conversacional' entre população (mães/crianças) e pesquisa, viabilizando, inclusive, a inserção de outros pesquisadores no campo. Conforme assinalado, nos momentos dialógicos ocorria uma interseção de trajetórias culturais; nessa perspectiva, os encontros sucessivos entre entrevistadoras de campo e informantes possibilitavam traçar uma trajetória de reconhecimento de hábitos das respectivas famílias/crianças e comunidades. 
As narrativas, histórias, casos sobre os hábitos de crianças e adultos iam se 'misturando' ao roteiro de investigação. Cada preenchimento de questionário significava uma atualização dialógica - cada número, ou melhor, cada sim (1), não (2), não sabe, não responde (99 NS/NR); em caso de sim, uma pergunta sobre por quê? - surgia no interior de um diálogo, em uma 'cadeia de comunicação' em que os interlocutores participavam ativamente da interação discursiva. Na prática concreta de investigação, de fato, os enunciados têm um endereço, antecipam uma resposta, ainda que estejam em uma 'região fronteiriça' de cooperação e resistência. Entretanto, na análise sobre produção de sentidos, pode-se afirmar que as estratégias disponíveis para a obtenção de respostas estendem e, ao mesmo tempo, limitam as possibilidades discursivas.

\section{Conclusão}

No campo da Saúde Coletiva, a teia narrativa tende a crescer e criar possibilidades de sentidos, principalmente com a circulação e demanda de novos agentes de discurso. Consolidando-se como "campo científico e âmbito de práticas aberto à incorporação de propostas inovadoras" (Paim E Almeida Filho, 2000, p.105), a Saúde Coletiva possibilita a edificação de "meta-pontos de vista" (Morin, 1994, p.433). Mais ainda, neste campo de práticas discursivas, ocorre uma mobilização contínua de meta-meta-pontos de vista sobre o objeto saúde, não apenas porque ocupamos uma posição (social e responsiva) no processo de produção de conhecimento encontramo-nos implicados no objeto de observação - mas também porque estamos engajados em uma rede cotidiana de participação de coletivos (diversos níveis de atividade) e de muitas "vozes" que se apresentam e se constituem dialogicamente. Nesta perspectiva, somos agentes de negociação (relacionais), não restritos às fronteiras disciplinares.

Quando levamos em consideração essa rede de comunicação cultural - e aqui ressalto a atualidade de Bakhtin, quando nos possibilita pensar sobre o imbricamento ou 'encadeamento' de vozes (textos e signos) - reconhecemos que os agentes/coletivos humanos - sujeitos sociais - em suas mais diversas trajetórias e formas de intercâmbios culturais, encontram-se engajados na mobilização de 'modelos' de saúde-enfermidade-cuidado. Cabe, então, destacar que nossos enunciados e inscrições são reconhecidos e objetivados por serem signos sociais. Portanto, estão investidos de historicidade, conformam hábitos, esforçam-se para traduzir uma linguagem em outra, adquirem novas formas (e qualidades), configuram e/ou alteram práticas culturais - sempre com o risco de produzir (novos) ruídos e interferências de comunicação.

Quanto a nós, agentes científicos no 'campo' da Saúde Coletiva, podemos produzir um espaço de conversação possível (transcientífica), na medida em que, como 'praticantes de ciência', possamos nos reconhecer também como agentes sociais, culturais e políticos, ainda que venhamos a nos expressar por meio de uma tradição ou formação diferenciada de linguagem, com nossas manufaturas/tecnologias e usos peculiares. Por outro lado, nossos enunciados e inscrições ${ }^{9}$ (tabelas, gráficos, mapas, rabiscos etc.) também não estão alheios ao mundo em que foram produzidos, ainda que haja uma incompletude ou movimento incessante de produção sígnica.

${ }^{9}$ Para Bruno Latour, nos textos científicos há tanto uma exposição visual quanto comentários dos cientistas. $\mathrm{Na}$ produção de inscrições ou síntese visual, imprescindíveis para o reconhecimento de um fato, "o efeito sobre a convicção é contundente, mas sua causa é mista, pois não conseguimos distinguir o que ver da coisa inscrita e o que vem do autor" (Latour, 2000, p.118-9). 
Esta postura crítica e reflexiva talvez seja o primeiro passo para o estabelecimento de canais de comunicação com outros sujeitos sociais, "na condição de parceiros e cidadãos", como enfatizam Paim \& Almeida Filho (2000, p.113).

Reitero, assim, o movimento ou diálogo simultâneo entre realidade e construção na produção do conhecimento científico; movimento este que implica sempre possibilidade de uma nova resposta ou, de acordo com a perspectiva bakhtiniana, continuação do diálogo em direção a um entendimento criativo. Este diálogo permanente ultrapassa uma postura representativa da realidade na medida em que a produção de conhecimento potencializa a circulação de novas ações, significados e uma infinidade de deslocamentos no cotidiano - incluindo a transformação do próprio objeto de conhecimento na cadeia de comunicação cultural. Por conseguinte, as diversas relações estabelecidas entre signos em contextos de mediação indicam a amplitude das possibilidades concretas de produção de sentidos no cotidiano $e$, mais especificamente, de sentidos de saúde.

\section{Referências}

BAKHTIN, M. Estética da criação verbal. São Paulo: Martins Fontes, 1997.

BAKHTIN, M. The dialogic imagination. Austin: University of Texas Press, 1998.

BAKHTIN, M. (Volochinov). Marxismo e Filosofia da Linguagem. São Paulo: Hucitec, 1999a.

BAKHTIN, M. Speech genres \& other late essays. Trad. Vern W. McGee. Austin: University of Texas Press, $1999 b$.

BRAIT, B. Bakhtin e a natureza constitutivamente dialógica da linguagem. In: BRAIT, B. (Org.). Bakhtin, Dialogismo e Construção do Sentido. Campinas: Editora da UNICAMP, 1997. p.97-104.

BURKITT, I. The death and rebirth of the author: the Bakhtin circle and Bourdieu on individuality, language and revolution. In: BELL, M. M.; GARDINER, M. (Eds.). Bakhtin and the human sciences. London: SAGE publications, 1998. p.163-80.

CLARK, K.; HOLQUIST, M. Mikhail Bakhtin. São Paulo: Perspectiva, 1998.

DANESI, M.; PERRON, P. Analyzing cultures: an introduction and handbook. Indiana: University Press, 1999.

DEELY, J. Semiótica básica. São Paulo: Ática, 1990.

ECO, U. Os limites da interpretação. São Paulo: Perspectiva, 1999.

GERGEN, K.J. La Construcción Social: Emergencia y Potencial. In: PAKMAN, M. (Org.). Construcciones de la Experiencia Humana. Barcelona: Gedisa Editorial, 1996. v.1, p.139-82.

GERGEN, K.J. Realities and relationships: soundings in social construction. Cambridge: Harvard University Press, 1997.

LATOUR, B. Ciência em ação. São Paulo: Ed. UNESP, 2000.

LATOUR, B.; WOOLGAR, S. A vida de laboratório: a produção dos fatos científicos. Rio de Janeiro: Relume-Dumará, 1997.

MACHADO, I. A. O romance e a voz: a prosaica dialógica de M. Bakhtin. Rio de Janeiro: Imago Ed., 1995.

MERRELL, F. Peirce, signs, and meaning. Toronto: University of Toronto Press, 1997. 
SILVA, L. A. V.

MERRELL, F. Introducción a la Semiótica de C.S. Peirce. Maracaibo: Universidad del Zulia, 1998.

MORIN, E. Epistemología de la Complejidad. In: SCHNITMAN, D. F. (Org.). Nuevos Paradigmas, Cultura y

Subjetividad. Buenos Aires: Paidos, 1994. p.421-42.

PAIM, J. S.; ALMEIDA FILHO, N. A crise da Saúde Pública e a utopia da Saúde Coletiva. Salvador: Casa da Qualidade Editora, 2000.

PEARCE, W.B. Nuevos modelos y metáforas comunicacionales: el pasaje de la teoría a la praxis, del objetivismo al construccionismo social y de la representación a la reflexividad. In: SCHNITMAN, D. F. (Org.).

Nuevos Paradigmas, cultura y sSubjetividad. Buenos Aires: Paidos, 1994. p.265-83.

PEIRCE, C. S. Semiótica. São Paulo: Perspectiva, 1999.

PICKERING, A. The mangle of practice: time, agency and science. Chicago: The University of Chicago Press, 1995.

SAMAJA, J. Semiótica y Dialéctica. Buenos Aires: JVE Ediciones, 2000.

SANTAELLA, L. Dialogismo: M. M. Bakhtin e C. S. Peirce: semelhanças e diferenças. Cruzeiro

Semiótico, n.2, p.5-13, 1985.

SANTAELLA, L. A teoria geral dos signos: como as linguagens significam as coisas. São Paulo: Pioneira, 2000.

SHOTTER, J. Cultural politics of everyday life: social constructionism, rhetoric and knowing of the third kind. Toronto: University of Toronto Press, 1993.

SHOTTER, J. El lenguaje y la construcción del sí mismo. In: PAKMAN, M. (Org.). Construcciones de la Experiencia Humana. Barcelona: Gedisa Editorial, 1996. v.1, p.213-25.

SHOTTER, J.; BILLIG, M. A bakhtinian psychology: from out of the heads of individuals and into the dialogues between them. In: BELL, M. M.; GARDINER, M. (Eds.). Bakhtin and the human sciences. London: SAGE publications, 1998. p.13-29.

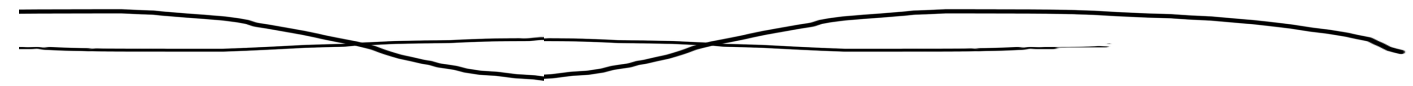

SILVA, L. A. V. Salud y producción de sentidos en lo cotidiano: prácticas de mediación y translingüística bakhtiniana, Interface - Comunic, Saúde, Educ, v.7, n.13, p.135-48, 2003.

Este artículo discute algunos conceptos y usos de la Semiótica en el campo de la Salud Colectiva, enfocando principalmente los textos del escritor ruso Mikhail Bakhtin. Estas consideraciones se refieren a tópicos específicos desarrollados después de mi participación en un proyecto de investigación etnográfica sobre la práctica de producción epidemiológica. En este artículo, se destaca la contribución de la Semiótica para el análisis de sentidos de salud. Se presenta una síntesis de fragmentos de narrativa como ejemplos de desplazamiento de textos de salud. Se resalta la actualidad de Bakhtin al hacernos pensar sobre la participación de los diferentes agentes como mediadores en la construcción de sentido. De esa forma, los agentes humanos - sujetos sociales - en sus diversas trayectorias culturales, se encuentran comprometidos en la producción de sentidos de salud-enfermedad-cuidado, pues comparten/ disputan/negocian puntos de vista o tendencias, en un proceso continuo de producción de sentidos.

PALABRAS CLAVE: Comunicación; Semiótica; Salud Colectiva; sentidos de salud; formación de conceptos. 